\title{
A Rare Dual Ovarian Tumor Mucinous Cystadenoma with Adult Granulosa Cell Tumor
}

\author{
Dr.Rooplata ${ }^{1}$, Dr.Yerramsetti Ananthalakshmi ${ }^{2}$ \\ 1. $3^{\text {rd }}$ year PG. Department of OBG, Raja rajeshwari Medical College and Hospital . \\ 2. Assistant Professor, Department of Surgery, Konaseema Institute of Medical Sciences \\ and Research Foundation.
}

\begin{abstract}
Dual tumor in an ovary is a rare entity and combination of mucinous cystadenoma with adult granulosa cell tumor (GCT) is very rare. Dual tumor represents a coexistence of two adjacent tumors but histologically distinct tumors without admixture in the same tissue or organ. Mucinous neoplasms occur rarely in association with granulosa cell tumor. GCT is low-grade malignancy and need a close follow up for recurrences which may be late. Here we present a case in 39 year old female who presented outpatient department with complaints of lower abdomen pain and dysfunctional uterine bleeding. Patient underwent hysterectomy with salphingo oophorectomy and specimen sent for histopathological examination, where it was diagnosed as mucinous cystadenoma in association with Adult granulosa cell tumor.
\end{abstract}

Key Words: Dual tumor, ovary, Mucinous Cystadenoma, Granulosa cell tumor.

\section{Introduction}

Adult granulosa cell tumor (GCT) accounts for 1-2\% of all ovarian neoplasm and they are known for late recurrences, even after 10-20 years in some cases.[1] Mucinous neoplasms occur rarely in association with granulosa cell tumor, cystic teratoma, Sertolileydig cell tumor and carcinoid tumor. [2] Dual tumors represent a coexistence of two adjacent but histologically distinct tumors without admixture in the same tissue or organ. Here we report a rare case of dual tumor comprising of mucinous cystadenoma in association with granulosa cell tumor in a 39 year old woman.

\section{Case Report}

Here we present a case of 39 year old female who presented outpatient department with complaints of lower abdomen pain and with irregular bleeding per vagina since six months. Ultra sonography findings showed a mass in the right ovary measuring $18 \times 12 \mathrm{cms}$ predominantly solid mass. Patient underwent hysterectomy with salphingo oophorectomy and specimen sent for histopathological examination, where it was diagnosed as mucinous cystadenoma in association with Adult granulosa cell tumor.

\section{Gross Findings}

The specimen showed enlarged right ovary measuring $18 \times 12 \mathrm{cms}$. The cut section of the ovary showed both solid and cystic areas.

\section{Microscopic Findings}

microscopically the sections studied showed features of both solid and cystic component. The solid component was highly cellular with closely packed sheets of cells, cells are round to oval cells lobulated by fibrous Septa. Cells showed eosinophilic cytoplasm and relatively uniform pale nuclei with prominent grooves. Call-Exner bodies were present at places as Adult granulosa cell tumor [figure 1] and cystic component showed that it was lined by a single layer of uniform mucin- filled tall columnar cells with basal nuclei, resembling endocervical epithelium, the features which were consistent with mucinous cystadenoma.[figure2].

\section{Discussion}

Dual tumors in an ovary represent a coexistence of two adjacent tumors but histologically distinct tumors without admixture in the same tissue or organ. Dual tumors in ovary are a rare entity and combination of mucinous cystadenoma and adult granulosa cell tumor is very rare. Though dual tumors in ovary have been reported earlier, like serous cystadenoma and mature cystic teratoma, [3] but combined mucinous cystadenoma and GCT was rarely reported. GCT and mucinous cystadenoma are independent tumor arising from sex cord stromal cells and surface epithelium of ovary, respectively.

Adult granulosa cell tumor (GCT) accounts for 1-2\% of all ovarian neoplasm and they are known for late recurrences, even after 10-20 years in some cases.[1] In the present case grossly it was cystic and there was small solid foci, which microscopically showed features of GCT and cystic component showed features of 
mucinous cystadenoma. Occasionally GCT presents as a small lesion in cystic teratoma which could easily be missed through inadequate sections, so ovaries with mature cystic teratoma should be examined thoroughly for small foci of GCT. [4]

Dual tumors have been described in various organs including oesophagus, stomach, liver, bone, kidney, brain and lung, such tumors involving the ovary are rare. At a molecular level, various cytogenetic abnormalities have been discovered in adult GCT. Trisomy 12 and 14, monosomy 22 are among the more prevalent ones. Aneuploidy has been correlated with a poorer survival. In addition, germ line P53 mutations have also been reported in these tumors. The prognostic significance of this mutation is, however, not known. Further research is needed before a definite conclusion is drawn regarding the clinical significance of these cytogenetic markers. $[5,6]$

To conclude, we would like to emphasize upon the fact that multiloculated cysts have to be extensively examined grossly, so as not to miss any solid component which might have a bearing on prognosis of the patient. However; in the present case the small solid foci showed the

features of GCT. GCT tumors are characterized by a very indolent course, and late recurrences.

This association of GCT and mucinous cystadenoma warrants close follow up of patient

as recurrences can occur many years after removal of primary tumor.

\section{References}

[1]. Spencer HW, Mullings AM, Char G, Carpenter R. Granulosa-theca cell tumors of the ovaries. A late metastasizing tumor. West Indian Med J 1999;48:33-5.

[2]. Russell P. surface epithelial stromal tumors of ovary. In: Kurman RJ, ed. Blaustein's pathology of the female genital tract. $4^{\text {th }}$ ed. New York: Springer-Verlag, 1994;724.

[3]. Ozgur B, Ahmet D, Meral KC, Mustafa S, Cagnur U et al. Collision tumor: serous cystadenoma and dermoid cyst in the same ovary. Archives of gynaecology and obstetrics 2009;279:767-70.

[4]. Dgani R, Rozenman D, Lifschitz-Mercer B. Granulosa cell tumorarising in an ovary with mature cystic teratoma. Int J Gynaecol Obstet1993;3:287-9.

[5]. Mayr D, Kaltz WC, Arbogast S et al. characteristic pattern of genetic aberrations in ovarian granulosa cell tumors. Mod Pathol 2002;15:951-7.

[6]. Nogales FF, Musto ML, Saez AI, Robledo M et al. Multifocal intrafollicular granulosa cell tumor of the ovary associated with an unusual germline p53 mutation. Mod Pathol 2004;17:868-73.

Figure 1: round to oval cells with eosinophilic cytoplasm and prominent nuclear grooves. (H\&E X400)

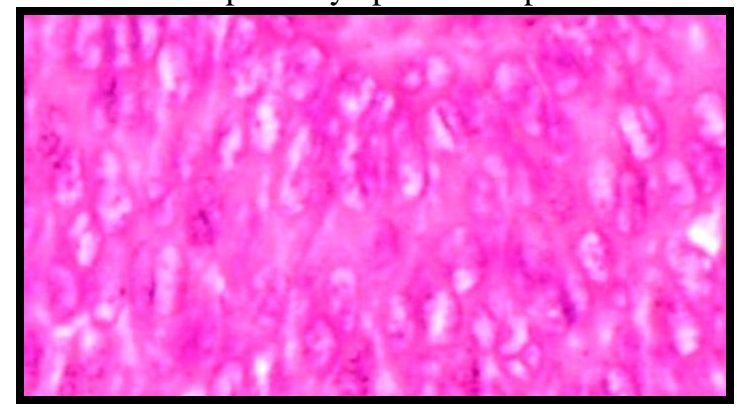

Figure 2: cystic component lined by a single row of uniform mucin-filled tall columnarcells with basal nuclei

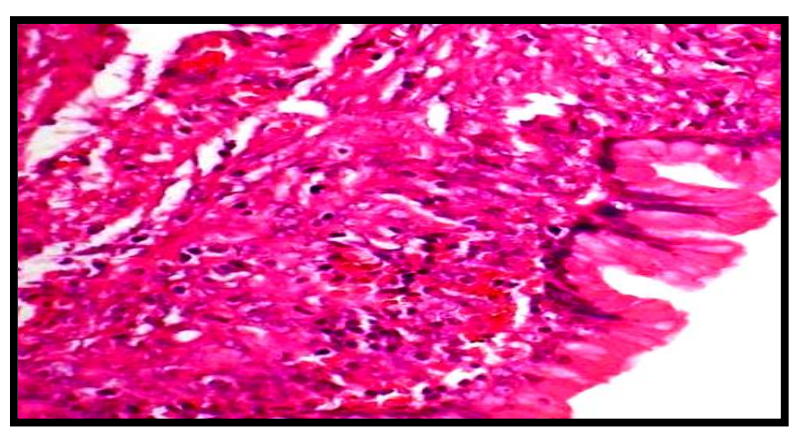

(H\&E X 100) 